\title{
A multidimensional analysis of the effects of innovation on the competitive advantage of small and medium-sized enterprises
}

\author{
Tarek Bel Hadja,b*
}

${ }^{a}$ Department of Business Administration, College of Business and Economics, Qassim University, Buraydah, Qassim, 52571,Saudi Arabia ${ }^{b}$ Faculty of Economics and Management of Sousse, University of Sousse, Tunisia

\section{CH R O N I C L E A B S T R A C T}

Article history:
Received: October 24, 2019
Received in revised format: No-
vember 282019
Accepted: December 22, 2019
Available online:
December 22, 2019
Keywords:
Product innovation
Process innovation
Marketing innovation
Organizational innovation
Competitive advantage
SMEs

\begin{abstract}
This paper investigates the effects of different dimensions of innovation on the competitive advantage of small and medium-sized enterprises (SMEs). The main dimensions of the innovation retained in this study are related to different types of innovation, innovation activities, sources of internal and external information, and public support for innovation. In this study, we rely on the principal component analysis of innovation applied to a sample of 231 Tunisian SMEs. The results show that product innovation, organizational innovation and innovation activities were the key variables for enhancing the competitive advantage of SMEs. In contrast, external sources of information have no effects on the SMEs competitive advantage. The originality of this research is to provide a multidimensional framework of the effects of innovation on the competitive position of SMEs.
\end{abstract}

C 2020 by the authors; licensee Growing Science, Canada

\section{Introduction}

Innovation is considered as an essential determinant of economic prosperity (Grossman \& Helpman, 1991, Griffith \& Van Reenen, 2004) and the competitiveness of SMEs (Distanont \& Khongmalai, 2018). In particular, innovation is considered as a key factor to develop the industrial activity of developed countries especially, and is one of the strongly connected element to business (Midler et al., 2012). Moreover, innovation is assimilated as an important factor of modernization, response to customer expectations, resorption of unemployment, and modernization of the economic fabric. Innovation is often perceived as the result of knowledge stock produced by inventors but recently, it is rather considered as the result of a process whose success is related to exchanges between a multitude of actors in situations of interdependencies (Landry et al., 2002). This concept has been identified by the OECD (2005) as the implementation of a product whether it is a good or service or a new or significantly improved process, an original method of marketing in the practices of workplace organization or external relations. This approach focused on the type and the purpose of the innovation. Contemporary studies tend to show that SMEs would innovate more in products than in processes (Hoffman et al., 1998). Other facets of innovation, such as marketing or organization method, are more limited. The common traits to all categories of innovation is that they must have been implemented in order to become innovations, and therefore, actually deployed and used in the market or by the company. The efforts made by an organization to innovate can be manifested through an investment that ultimately promotes its success. Nevertheless, any kind of innovation contains risk taking. Thus, innovation does not mean its success and this requires the study of its relationship with the competitive advantage of companies. In the previous literature, the link between innovation 
and performance is not easily argued. Innovation can take different forms. The best-known forms were focused on product, process, marketing, organizational and technological innovation (Ganzer et al., 2017). The economic benefits of innovation in the service sector was also increasingly recognized (OECD, 2005). In this regard, Howells (2004a,b) divided them into four groups: goods-related services (e.g., transportation, logistics), information-related services, knowledge-based services, and personal services (e.g. health care). Product innovation is the most documented category in the literature. Process innovation refers to the introduction of newly introduced methods or the significant development of existing methods in the company's production and distribution activities. These methods may concern technical, hardware or software resources. Process innovation can also include business support activities, such as purchasing, accounting, calculation or maintenance. Marketing innovation refers to the implementation of a new technique which can change the design or packaging of products, their placement at the point of sale and their mode of promotion or their approach of pricing. To this end, the provision of marketing capabilities made possible by the availability of adequate strategic resources is likely to ensure the survival of companies and facilitate its development and performance (Nuryakin et al., 2018). In addition, organizational innovation reflects a change in business behavior, in the workplace organization or in the manner that external relations are managed. Actually, organizational innovation is considered as an indispensable lever to achieve technological performance (OECD, 2005). Despite this plurality of innovation-specific dimensions, the majority of research focused on one or some of these dimensions to analyze its effects on the competitive advantage of SMEs. The contribution of our study lies in the use of a multidimensional approach in order to test the effects of innovation on the competitive advantage of SMEs.

This paper is structured as follows: In the first section, we present the literature review on the relationship between innovation and SMEs competitiveness. Then, we expose our research methodology. Finally, we present the results, discussion, conclusion, and principal implications.

\section{Literature review}

Many studies have shown positive effects of the innovation on the economic and financial performance of SMEs. In this regard, Hult et al. (2004), which closely linked the innovation of 181 US industrial companies to different forms and types of strategic performance (profitability, growth, market shares, overall performance). Huang and Liu (2005), based on a study carried out on 297 large Taiwanese companies, showed that the innovative capital of companies calculated on the basis of R \& D rates, is correlated with the financial performance of SMEs. More recently, Jacob et al. (2018) showed, in the case of Ghana and based on a sample of 340 SMEs, positive effects of innovative capacity on financial performance. The study of Distanont and Khongmalai (2018) based on a structural equation model applied to a sample of 279 SMEs belonging to the frozen food industry showed that external factors of innovation lead to competitive advantage of SMEs. However, other avenue of research has not found positive effects of innovation on the economic and financial performance of SMEs. For this purpose, Dibrell et al. (2008), based on a sample of 311 US SMEs, found no direct link between the two types of product and process innovations, and performance, measured by the profitability rate and the growth rate. For their part, Jansen et al (2006), based on a survey of 238 SMEs, found no direct effect of exploration or exploitation of innovations on financial and strategic performance. According to this last line of research, it was necessary to have an optimal threshold of R \& D investment carried by SMEs, and the fact of positioning above or below affected differently the performance of the SME. In fact, innovation was connected to the SME performance through the theory of resource-based view. This theory indicated that the economic and financial performance of the company needs a combination of resources and capabilities. These resources are considered as the main sources of competitive advantage of the companies (Wernerfet, 1984; Barney, 2000). This resource approach to explain the benefits of innovation may be relevant to SMEs (Hadjimanolis, 2000). In the literature, it is well documented that the most innovative companies use a wide variety of information sources (Hartman et al., 1994). According to Julien et al. (2009), this need for information, especially precompetitive information, acquired before competition is essential in both developing and industrialized countries, unless these firms operate in very distinctive niches.

From an evolutionist perspective, organizations first accumulate information and experiences that foster the generation of innovations (Cohen \& Levinthal, 1990), and then develop routines and structures that crystallize organizational knowledge and are perfected with the time to use the information and knowledge more effectively. Routines and structures, however, are difficult to change. Faced with a rapidly changing environment, the slow adjustment of routines and structures becomes a source of organizational inertia and rigidity. Numerous empirical studies have studied the impact of public support for innovation in general and in particular for SME innovation (Piza et al., 2016). The study of the impact of public interventions usually consists of estimating a function of the type:

Endogenous variable measuring efficiency $=\mathrm{F}$ (Public support, other variables)

In this case, public and private research complement each other if the public effort translates into an increase in net private effort (i.e. excluding public support). They are substitutable if the public effort leads to a decrease in private efforts, thus leading to a process of eviction. Finally, the impact of public action is neutral or insignificant when the public effort adds to the private effort without modifying it. At the end of this literature, we can advance the following hypotheses concerning the role of innovation in determining the competitive advantage of SMEs. 
$\mathbf{H}_{1}$ : The type of innovation significantly affects the competitive advantage of SMEs.

$\mathbf{H}_{2}$ : The competitive advantage of SMEs is positively influenced by the innovation activities.

$\mathbf{H}_{3}$ : The public support for innovation is crucial to achieve the competitive advantage of SMEs.

$\mathbf{H}_{4}$ : The competitive advantage of SMEs is positively influenced by internal and external information sources.

\section{Research Methodology}

Our data were collected through a questionnaire sent electronically to a population of 250 Tunisian SMEs. Following a process of filtering missing or outliers, we are limited to a sample of 231 SMEs. We apply the Likert scales to approximate each of the items related to types of innovation, innovation activities, sources of information and public support for innovation. These scales are measured by values ranging from 0 to 5 according to the respondents' attitudes regarding each of the items selected. To test the validity and the reliability of the items mentioned above, we based on the study of the Cronbach coefficient (Cronbach's alpha) and try to examine the unidimensional character of the scales on the basis of the principal components analysis (PCA). For this purpose, with respect to the Cronbach coefficient, we have retained the value of 0.6 as the minimum threshold of significance and thus, to accept or not the internal coherence of the items. The choice of this value is consistent with the size of our sample as recommended by Moss et al. (1998) and Hair et al. (2006). We used 0.5 to eliminate items whose contributions are less than or equal to this value. Finally, to validate our hypotheses of research we resorted to the tests of the normality (based on the coefficients of asymmetric and flattening) and the tests of hierarchical regression. In view of this, the appropriate statistical tests should be mobilized. The data was processed and carried out using the output of the MINITAB software. The standardized Varimax method is used. Flattening and asymmetry indicators were analyzed. Some measurement variables cannot be considered pseudo-normal. As a result, we preferred to use a cleaned projection procedure (saturation). In this research, we rely on the general approach of Gomes et al. (2009) to measure the variable related to competitive advantage. These authors showed that competitive advantage is largely related to the company's market leadership, production, innovation and efficiency or service. As a result, competitive advantage items are formulated by price advantage, product quality, product differentiation and product suitability. The items selected from the various variables relating to the type of innovation, internal and external sources of information, public support for innovation, and innovation activities are presented in detail in Tables 2, 3, 4 and 5, respectively.

\section{Results and discussion}

In what follows, we try to test the validity, internal consistency and reliability of the items selected for each of the variables relating to the types of innovation, innovation activities, sources of information, and public support for innovation. Table 1 presents the correlation between the key variables of our study as well as the set of the descriptive statistics. From this table, a strong correlation exists between the competitive advantage (CA) as dependent variable and each of the independent variables which are: product innovation (PDI), process innovation (PCI), marketing innovation (MI), organizational innovation (OI), public support for innovation (PS), internal information sources (IIS) and external information sources (EIS). These results therefore make it possible to predict significant effects of each of the variables retained on the competitive advantage.

Table 1

The Summary statistics

\begin{tabular}{|c|c|c|c|c|c|c|c|c|c|}
\hline & EIS & IIS & PDI & PCI & OI & MI & PS & IA & CA \\
\hline CA & 0.732 & 0.601 & 0.556 & 0.819 & 0.648 & 0.533 & 0.912 & 0.915 & 1 \\
\hline IA & 0.642 & 0.600 & 0.472 & 0.642 & 0.616 & 0.334 & 0.905 & 1 & \\
\hline PS & 0.771 & 0.713 & 0.552 & 0.789 & 0.677 & 0.469 & 1 & & \\
\hline MI & 0.429 & 0.153 & 0.300 & 0.653 & 0.529 & 1 & & & \\
\hline OI & 0.553 & 0.497 & 0.236 & 0.588 & 1 & & & & \\
\hline PCI & 0.771 & 0.610 & 0.574 & 1 & & & & & \\
\hline PDI & 0.552 & 0.442 & 1 & & & & & & \\
\hline IIS & 0.735 & 1 & & & & & & & \\
\hline EIS & 1 & & & & & & & & \\
\hline Mean & 29.058 & 10.800 & 6.143 & 9.001 & 8.093 & 8.706 & 73.151 & 10.571 & 7.876 \\
\hline Median & 29.473 & 11.247 & 6.804 & 9.368 & 8.661 & 9.233 & 75.838 & 11.008 & 8.627 \\
\hline Maximum & 34.89 & 15.937 & 7.697 & 11.24 & 10.364 & 11.143 & 93.882 & 12.94 & 9.416 \\
\hline Minimum & 19.284 & 4.69 & 2.509 & 3.723 & 4.367 & 3.502 & 31.443 & 2.588 & 2.830 \\
\hline Std. dev & 3.384 & 2.661 & 0.937 & 2.029 & 1.704 & 1.684 & 13.004 & 2.495 & 1.560 \\
\hline
\end{tabular}

As shown in Table 2, four factorial axes are retained since the percentage of inertia explained by these axes is of the order of $88.9 \%$ and presenting eigenvalues greater than 1 . This percentage reflects that the eigenvalues of the axes retained give a good proportion of the analysis because the sum of the inertia explained by each of the axes represents a significant part of the total inertia. Moreover, the factor analysis conducted on the items specific to the four types of innovation showed that the first factorial axis is essentially represented by the items relating to organizational innovation. Indeed, these items each have at least a factorial weight of the order of 0.766 . The variance explained by this factorial axis is $29.2 \%$ of the total variance explained. 
Table 2

Principal component analysis of the variable relating to the types of innovation: Factor weights (Varimax Standardized)

\begin{tabular}{|c|c|c|c|c|}
\hline Items & Fact. 1 & Fact. 2 & Fact. 3 & Fact. 4 \\
\hline Production of goods & 0.200 & 0.099 & 0.083 & 0.808 \\
\hline Provision of services & 0.126 & 0.119 & 0.137 & 0.893 \\
\hline Processes for the manufacture or production of goods or services & 0.009 & -0.107 & 0.959 & -0.147 \\
\hline Methods of logistics, supplies or distribution of raw materials & -0.046 & -0.079 & 0.913 & 0.081 \\
\hline Support activities for processes & 0.041 & -0.111 & 0.938 & -0.153 \\
\hline Knowledge management systems & 0.888 & 0.156 & 0.008 & 0.287 \\
\hline A major change in the organization of work within company & 0.766 & 0.107 & 0.005 & 0.221 \\
\hline Changes in relationships with other companies or public institu- & 0.937 & 0.097 & 0.017 & 0.161 \\
\hline Significant changes related to the design or packaging of goods & 0.142 & 0.955 & 0.135 & 0.077 \\
\hline New methods of sale or distribution & 0.083 & 0.925 & 0.094 & 0.087 \\
\hline New pricing or technical strategies for the products & 0.111 & 0.667 & -0.031 & 0.136 \\
\hline Variance explained & 3.503 & 2.776 & 2.693 & 1.695 \\
\hline Tot. Prop. & 0.292 & 0.231 & 0.224 & 0.141 \\
\hline Cronbach's alpha & \multicolumn{4}{|c|}{0.687} \\
\hline
\end{tabular}

The items related to the variables of innovation of product, innovation of process, organizational innovation and marketing innovation respectively form the four other factorial axes which respectively explain $29.2 . \%, 23.1 \%, 22.4 \%$. and $14.1 \%$ of the total variance explained. The minimum factor weight of the items specific to these variables is 0.677 . In addition, our results showed a Cronbach coefficient of 0.687 which reflects a satisfactory result since it exceeds the acceptance threshold set in our study thus reflecting the reliability of the items selected. These results lead to retain all the items measuring the types of innovation. From the 15 items of the questionnaire, the factor analysis revealed a three-factor solution which is in line with expectations, for a total explained variance of $84 \%$. Moreover, the factor analysis carried out on the items specific to the three forms of information sources showed that the first factorial axis is essentially represented by items relating to external sources of information. Indeed, each of these items has at least a factorial weight of the order of 0.593 . The variance explained by this factorial axis is $52.4 \%$ of the total variance explained. The variables relating to internal information sources and generally available sources of information respectively form the two other factorial axes which respectively explain $23.7 \%$ and $7.9 \%$ of the total variance explained. To confirm the homogeneity of each of these dimensions, we performed the Cronbach's alpha test. Table 3 indicated that the reliability of Cronbach coefficient is slightly higher than the selected threshold (0.825). So, it is all the more acceptable that this scale is exploratory.

Table 3

Principal component analysis of the variable relating to information Sources: Factor weights (Varimax Normalized)

\begin{tabular}{|c|c|c|c|}
\hline Items & Fact. 1 & Fact. 2 & Fact. 3 \\
\hline Research-Development Staff & -0.05 & 0.977 & 0.015 \\
\hline Sales and marketing staff & -0.006 & 0.913 & -0.085 \\
\hline Production staff & -0.047 & 0.918 & -0.045 \\
\hline Management staff & 0.018 & 0.941 & 0.026 \\
\hline Related Business Group Businesses & 0.948 & -0.029 & 0.256 \\
\hline Suppliers of equipment, materials and components & 0.877 & -0.051 & 0.253 \\
\hline Customers & 0.858 & 0.042 & 0.136 \\
\hline Competitors & 0.855 & & 0.216 \\
\hline Consulting Firms & 0.903 & -0.075 & 0.145 \\
\hline Universities and colleges & 0.593 & -0.058 & 0.120 \\
\hline Organizations and research laboratories & 0.691 & -0.084 & 0.181 \\
\hline Fairs and exhibitions & 0.148 & -0.029 & 0.756 \\
\hline Internet or computer information networks & $0 . .128$ & -0.1 & 0.734 \\
\hline Congresses and professional meetings, publications & 0.077 & 0.055 & 0.756 \\
\hline Other sources of information & 0.046 & -0.016 & 0.750 \\
\hline Variance explained & 0.524 & 0.237 & 0.079 \\
\hline Total Prop. & 7.85 & 3.55 & 1.192 \\
\hline Cronbach's alpha & \multicolumn{3}{|c|}{0.825} \\
\hline
\end{tabular}

The percentage sum of $84 \%$ reflects the reliability of the reading of the "mappings" (projections) and therefore of a good overall quality that explains the analysis. Before proceeding with the principal component analysis, we first tested whether the conditions concerning the factorization of the variables were respected. The statistics of the correlation anti-image matrix are satisfactory $(>0.50)$ and the Bartlett sphericity test is significant at the 0.001 threshold in all three cases. We reject the assumption of sphericity of the data. From the 26 items, the Scree test of Cattell and Vogelmann (1977) revealed a 3-factor structure. These three factorial structures obtained (12 items, 8 and 6 items, respectively) account for approximately $82.4 \%$ of the variance and therefore appear to be satisfactory. The three solutions chosen are very close in terms of both adjustment and explanatory power. The tri-factorial structure represents respectively the following items: The problems of access to information on public financing, public financial support and government support programs. Moreover, the factor analysis conducted on the items specific to public support showed that the first factorial axis is essentially represented by the items 
relating to the possible problems of access to information on public financing. Indeed, each of these items has at least a factorial weight of the order of 0.839 . The variance explained by this factorial axis is $31.8 \%$ of the total variance explained.

\section{Table 4}

Principal component analysis of the variable relating to public support for innovation: Factor Weights (Varimax Standardized)

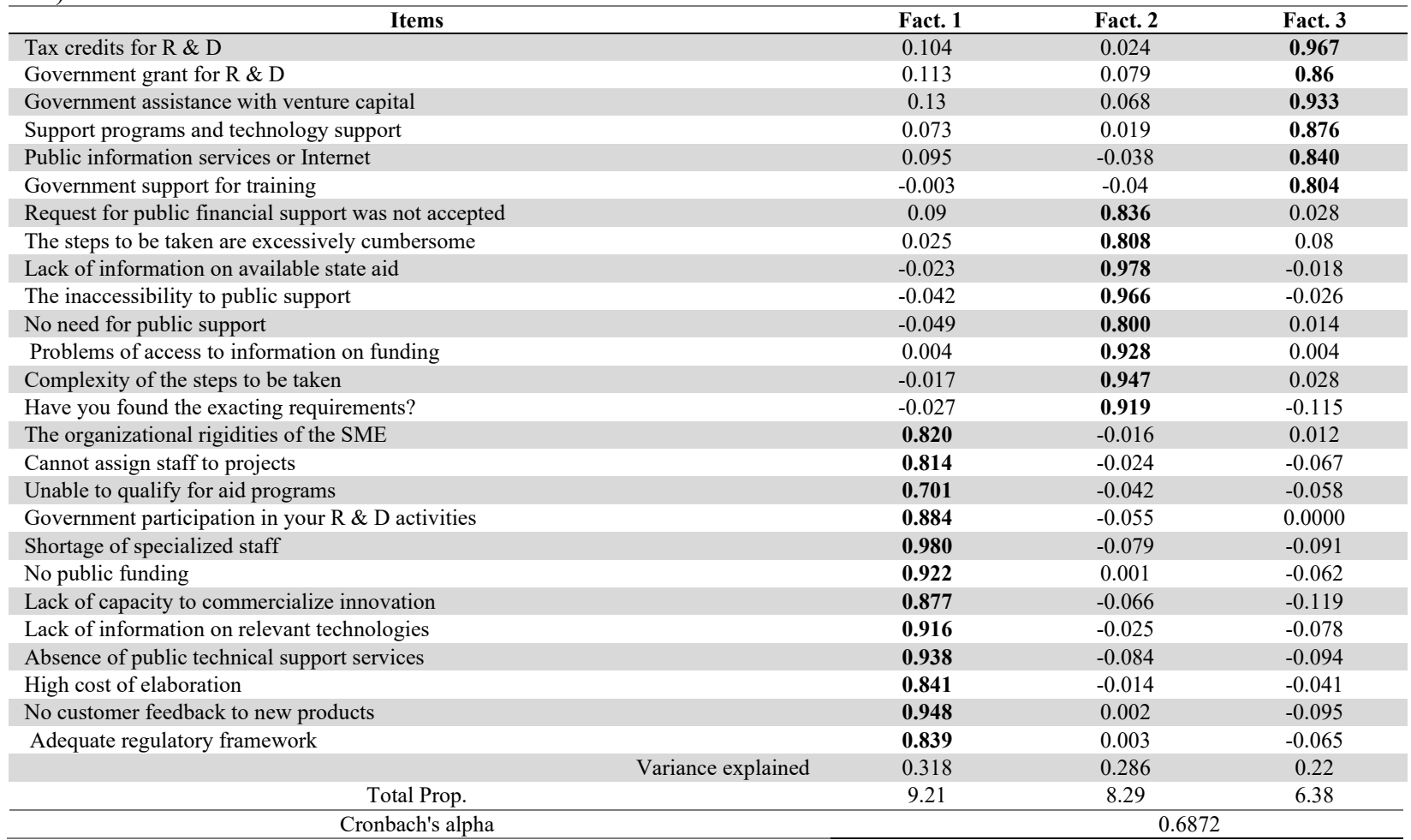

From the four items selected for testing this scale, the factor analysis revealed a one-dimensional solution. The total explained variance is $84.6 \%$ and the lowest factor weight is 0.554 . All statistics of the sampling accuracy from the anti-image matrix of the correlations are greater than 0.50 . The factorial structure obtained, validated by the confirmatory analysis and relating to the innovation activities variable, is presented in Table 5.

\section{Table 5}

Principal components analysis of the variable relating to innovation activities: Factor Weights (Varimax Standardized)

\begin{tabular}{lc}
\hline \multicolumn{1}{c}{ Items } & Fact. 1 \\
\hline Patent deposits & 0.576 \\
Acquisition of advanced machinery, computer hardware or software & 0.678 \\
Purchase of rights to use patents and non-patented inventions & 0.78 \\
Internal and / or external training of the staff to develop and / or introduce new processes or products & 0.554 \\
\hline
\end{tabular}

In the following, we will try to test the hypotheses $\mathrm{H}_{1}, \mathrm{H}_{2}, \mathrm{H}_{3}$, and $\mathrm{H}_{4}$. The approach used consists of two steps: Initially we seek to validate our two principal hypotheses concerning the effects of the types of innovation and innovation activities on competitive advantage. In a second step, we try to test the improvement of the competitive advantage following the addition of the complementary variables relating to public support for innovation and internal and external sources of information. In this respect, we used hierarchical regression analysis to test our hypotheses. In the first model (model 1) we integrated the competitive advantage as a dependent variable and the four types of innovation as well as the innovation activities as independent variables. As a first step, the four traditional types of innovation have been integrated into our model namely: "product Innovation", "process Innovation", "organizational Innovation", and "marketing Innovation" next to the variable relating to "innovation activities". Then, we retained an expanded model (model 2) in which we added the internal and external sources of information as well as the public support for innovation as a second step. The results are detailed in Table 6 which presents the marginal contribution to the prediction of the competitive advantage of each of the variables selected. 
Table 6

The Marginal contribution to the prediction of the competitive Advantage of SMEs

\begin{tabular}{llcc}
\hline \multicolumn{1}{c}{ Model } & \multicolumn{1}{c}{ Beta(t) } & \multicolumn{1}{c}{ Model 1 } \\
\hline & & & \\
Product innovation & $0.023^{* *}$ & & \\
Process innovation & 0.403 & 0.874 & $254.03 * * *$ \\
Organizational innovation & $0.042^{2}$ & & \\
Marketing innovation & 0.270 & & \\
Innovation activities & $0.857^{* *}$ &
\end{tabular}

Model 2

\begin{tabular}{lll} 
Product innovation & $0.282^{* * *}$ & \\
Process innovation & $0.125^{* * *}$ & \\
Organizational innovation & 0.290 & 0.02 \\
Marketing innovation & $0.425^{*}$ & $128.27 * * *$ \\
Innovation activities & 0.437 & \\
Internal sources of information & $0.187^{*}$ & \\
External sources of information & 0.185 & \\
Public support for innovation & $0.191 * *$ & \\
\hline$(*) ;(* *) ;(* * *) ;$ Significance threshold at $10 \% ; 5 \% ;$ and $1 \%$, respectively.
\end{tabular}

The F-statistic showed that the first model and the second model are both globally significant. However, the coefficient of determination of the second model in which the competitive advantage of SMEs is explained by the types of innovation, innovation activities, sources of information and public support is very low $\left(\Delta \mathrm{R}^{2}=0.02\right)$. This result indicated that the second model has a poor quality of fit. This model remains interpretable. In opposition, the first model presented a good quality of adjustment $\left(\Delta \mathrm{R}^{2}=0.874\right)$.

In this regard, our estimates of the first model showed that the competitive advantage of SMEs is significantly and positively explained by product innovation $($ Beta $=0.023)$, organizational innovation $($ Beta $=0.042)$ and the innovation activities. With the addition of the variables related to the sources of information and public support for innovation, the variable relating to innovation activities has no significant effect on competitive advantage of SMEs. This result reflects a possibility of mediation (as shown by Baron and Kenny, 1986) of the variables specific to sources of information and public support for innovation in the relation between types of innovation and innovation activities, and competitive advantage. This justifies the poor quality of adjustment of the second model, since the indirect effects of internal and external sources of information as well as innovation activities had to be integrated into the expanded model.

\section{Conclusion and implications}

Innovation remains an ability to engage in the strategic performance of companies and is an essential feature of organizations, affecting both SMEs and large firms. The production of innovation concerns all companies, and is a decisive variable for the success of their strategies. In this research, we asked about the impact of different types and innovation activities on the performance of SMEs. Our empirical results revealed positive and significant effects of product innovation, organizational innovation, and innovation activities on the competitive advantage of SMEs. As a result, in terms of innovations to be implemented, a set of challenges is important for SMEs in order to achieve a competitive advantage, namely: Encourage the development of new products and the provision of services.

Moreover, in order to succeed in their strategies, it is essential for SMEs to implement new manufacturing or production processes, logistical means, new sources of raw materials; knowledge management systems, new sales or distribution methods, new pricing strategies for products. In addition, SMEs are required to make a major change in workplace organization, and to build strong relationships with other businesses or public institutions. In addition, the competitive advantage of SMEs depends on their technological production activities through the patent deposits or the acquisition of advanced machinery, computer hardware or software, and the purchase of rights to use patents and non-patented inventions, and internal and / or external training of personnel to develop and / or introduce new processes or products. 


\section{References}

Distanont, A., \& Khongmalai, O. (2018). The role of innovation in creating a competitive advantage. Kasetsart Journal of Social Sciences. DOI: 10.1016/j.kjss.2018.07.009

Barney, J. B. (2000). Firm resources and sustained competitive advantage. In Economics Meets Sociology in Strategic Management (pp. 203-227). Emerald Group Publishing Limited.

Baron, R. M., \& Kenny, D. A. (1986). The moderator-mediator variable distinction in social psychological research: Conceptual, strategic, and statistical considerations. Journal of personality and social psychology, 51(6), 1173.

Cattell, R. B., \& Vogelmann, S. (1977). A comprehensive trial of the scree and KG criteria for determining the number of factors. Multivariate Behavioral Research, 12(3), 289-325.

Cohen, W., \& Levinthal, D. A. (1990). Absorptive capacity: a new perspective on learning and innovation. Administrative Science Quarterly, 35(1), 128-152.

Dibrell, C., Davis, P.S., \& Craig, J. (2008). Fueling innovation through information technology in SMEs. Journal of Small Business Management, 46(2), 203-218.

Ganzer, P. P., Chais, C., \& Olea, P. M. (2017). Product, process, marketing and organizational innovation in industries of the flat knitting sector. RAI Revista de Administração e Inovação, 14(4), 321-332.

Gomes, C.F., Yasin, M.M. \& Lisboa, J.O.V. (2009). Benchmarking competitive methods and strategic choices of Portuguese SMEs. Benchmarking: An International Journal of Agribusiness in Developing and Emerging Economies, 16(6), 729740.

Griffith, R., Redding, S., \& Reenen, J. V. (2004). Mapping the two faces of R\&D: Productivity growth in a panel of OECD industries. Review of Economics and Statistics, 86(4), 883-895.

Grossman, G. M., \& Helpman, E. (1993). Innovation and growth in the global economy. MIT press.

Hadjimanolis, A. (2000). A resource-based view of innovativeness in small firms. Technology Analysis \& Strategic Management, 12(2), 263.

Hair, J., Black, W., Babin, B., Anderson, R., \& Tatham, R. (2006). Multivariate data analysis (6th ed.). Uppersaddle River, N.J.: Pearson Prentice Hall.

Hartman, E. A., Tower, C. B., \& Sebora, T. C. (1994). Information sources and their relationship to organizational innovation in small business. Journal of Small Business Management, 32, 36-47.

Hoffmann, K., Kaiser, W., Isermann, M., \& Priebe, S. (1998). Changes in quality of life in long-term hospitalised psychiatric patients after discharge. (In German). Gesundheitswesen, 60, 232-238.

Howells, J. (2004a). Innovation, consumption and services: encapsulation and the combinatorial role of services. The Services Industries Journal, 24, 19-36.

Howells, J. (2004b). Services and innovation: conceptual and theoretical perspectives. In Daniels, P. and Bryson, J. (Eds.) The Handbook of Service Industries Edward Elgar, Cheltenham.

Huang, C.J., \& Liu, C.J. (2005). Exploration for the relationship between innovation, IT and performance. Journal of Intellectual Capital, 6(2), 237-52.

Hult, G. T. M., Hurley, R. F., \& Knight, G. A. (2004). Innovativeness: Its antecedents and impact on business performance. Industrial Marketing Management, 33(5), 429 - 438.

Jacob, D., George, N. A. D., Collins, K. K., \& Eunice, A. (2018). Innovative capability, strategic goals and financial performance of SMEs in Ghana. Asian Pacific Journal of Innovation and Entrepreneurship, 12(2), DOI: 10.1108/APJIE-102017-0033.

Jansen, J.J.P., van den Bosch, F.A.J., \& Volberda, H.W. (2006). Explorative innovation, exploitative innovation, and performance: effects of organizational antecedents and environmental moderators. Management Science, 52(11), 1661-1674.

Julien, P.-A., C. Leyronas, Makita, J., \& Moreau, E. (2009). La capacité d'absorption, l'élément clé dans la compréhension de la relation entre information et innovation, le cas des PME du Congo-Brazzaville. Revue internationale PME, 22 (2), 133-168.

Landry, R., Amara, N., \& Lamari, M. (2002). Does social capital determine innovation? To what extent?. Technological Forecasting and Social Change, 69, 681-701

Midler, C., Beaume, R., \& Maniak, R. (2012). Réenchanter l'industrie par l'innovation. Paris: Dunod.

Moss, H. E, Tyleff, L. K., Durrant-Peatfield, M., \& Bunn, E. (1998). Two eyes of a see-through: Impaired and intact semantic knowledge in a case of selective deficit for living things. Neurocase, 4, 291-310.

Nuryakin, N., Aryanto, V.D.W. \& Setiawan, M.B. (2018). Mediating effect of value creation in the relationship between relational capabilities on business performance. Contaduría y Administracion, 63(1), 1-21.

OECD/Eurostat, (2005). Oslo Manual, Guidelines for Collecting and Interpreting Innovation Data. OECD Publishing, Paris (2005)

Piza, C., Cravo, T. A., Taylor, L., Gonzalez, L., Musse, I., Furtado, I., Sierra, A. C., \& Abdelnour, S. (2016). The impact of business support services for small and medium enterprises on firm performance in low- and middle-income countries: $A$ Systematic Review. Campbell Systematic Reviews, 12(1), 1-167. 
Wernerfelt, B. (1984). A resource-based view of the firm. Strategic Management Journal, 5, (March), 171-180.

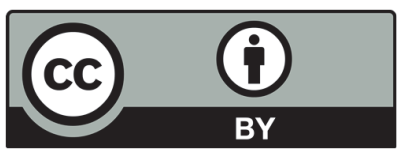

(C) 2020 by the authors; licensee Growing Science, Canada. This is an open access article distributed under the terms and conditions of the Creative Commons Attribution (CC-BY) license (http://creativecommons.org/licenses/by/4.0/). 